\title{
Wertorientierung und Kostenrechnung
}

Wertorientierte Unternehmensführung oder die Steigerung des shareholder value ist in aller Munde. Kaum ein börsennotiertes Unternehmen, das nicht wertorientierte Steuerungskonzepte oder an der Wertsteigerung orientierte Anreizsysteme implementiert hat. Wenn auch die mit der konzeptionellen Gestaltung von Wertbeitragskennzahlen oder wertorientierten Anreizsystemen verbundenen Fragestellungen keineswegs vollständig geklärt sind, hat man aus theoretischer und praktischer Sicht ein gesichertes Fundament, von dem aus offene Fragen gelöst werden können. Dieses gesicherte Fundament fehlt hingegen weitgehend bei Fragen der Umsetzung und der Integration von wertorientierten Steuerungskonzepten in das bestehende Rechnungswesen, insbesondere die Kostenrechnung.

Dass eine solche Integration notwendig ist, damit die Wertorientierung nicht als Worthülse verkommt, sondern in den Unternehmen aktiv gelebt werden kann, dürfte jedoch unbestritten sein. Schließlich ist die Frage der operativen Leistungsfähigkeit die Herausforderung, die heute von den Unternehmen gelöst werden muss. Dazu müssen die wertorientierte Spitzenkennzahl, unabhängig davon für welches der Konzepte man sich entschieden hat, und die mit ihr verbundenen finanziellen Kennzahlen in operative Mess- und Steuerungsgrößen transformiert werden. Die Verknüpfung finanzieller und operativer Kennzahlen wird in der Zukunft die größte Herausforderung bei der Gestaltung von Controllingsystemen sein.
Dabei liegt die Integration der wertorientierten Unternehmensführung in neuere Konzepte des strategischen Kostenmanagement eigentlich auf der Hand. Konzepte der Lebenszykluskostenrechnung lassen sich hervorragend mit dem Gedanken der Wertorientierung verbinden, wird doch mit der Lebenszykluskostenrechnung ein langfristiges Konzept verfolgt, um den Erfolg von Produkten zu beurteilen. Allein schon wegen des Zeithorizonts besteht eine Übereinstimmung von strategischem Kostenmanagement und wertorientierter Unternehmensführung. Aber auch die Prozesskostenkostenrechung liefert mit ihrer Orientierung an Kostentreibern einen geeigneten Anknüpfungspunkt, der nicht nur in der sprachlichen Nähe zu den Werttreibern liegt. Vielmehr eröffnet sich die Chance, mit Hilfe der Kostentreiber, die Werttreiber auf die operative Ebene zu transformieren. Damit wird es uns möglich, Konzepte der wertorientierten Unternehmensführung mit bestehenden Instrumenten der Kostenrechnung zu verbinden.

Beide Entwicklungen zeigen auch die Entwicklung und Bedeutung der Kostenrechnung für das Management. Die Kostenrechnung dient nicht allein einer Kalkulation oder der kurzfristigen Erfolgskontrolle. Sie ist mittlerweile als ein strategisches Führungsinstrument zu verstehen. Aus dieser veränderten Perspektive, verbunden mit der notwendigen Integration in wertorientierte Führungssysteme ergeben sich für den Controller, aber auch für die Wissenschaft neue Herausforderungen in der Zukunft. Die Zeitschrift für Controlling und Management fühlt sich dieser Entwicklung besonders verpflichtet und möchte Ihnen als Rat- und Ideengeber dienen.

Aber lassen wir eins nicht in Vergessenheit geraten: Die Wertorientierung der Unternehmensführung ist mehr als die Formulierung von (zum Teil überhöhten) Renditezielen, das Kürzen von Ausgaben

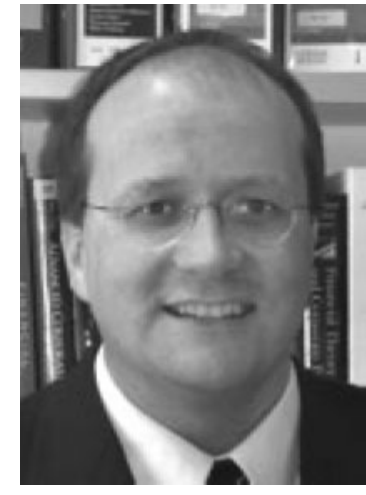

Prof. Dr. Dirk Hachmeister

und das Entlassen von Mitarbeitern. Hier zeigt sich eine bedauernswerte Kommunikationslücke, wird doch eine wertorientierte Unternehmensführung oftmals allein als Renditeziel formuliert, das der Kapitalmarkt erwarten würde. Neben der Frage nach der konkreten Höhe einer entsprechenden Zielvorgabe wird mit einer solchen Sichtweise auch ein kurzfristiges Erfolgsziel stark in den Vordergrund gesetzt. Der Kapitalmarkt liefert jedoch allen Unkenrufen zum Trotz eine langfristige und nachhaltige Perspektive. Langfristig kann man nur durch Investitionen und Wachstum Unternehmenswerte schaffen und steigern. Ideen und Kreativität sind dazu ebenso notwendig wie die sinnvolle Gestaltung des Rechnungswesens und des Controllings.

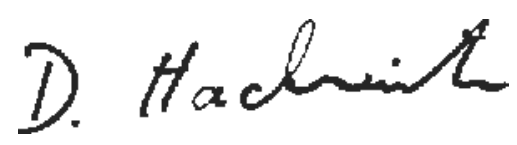

Ihr Dirk Hachmeister 